\title{
SCH9, a gene of Saccharomyces cerevisiae that encodes a protein distinct from, but functionally and structurally related to, cAMP-dependent protein kinase catalytic subunits
}

\author{
Takashi Toda, ${ }^{1}$ Scott Cameron, Philip Sass, ${ }^{2}$ and Michael Wigler ${ }^{3}$ \\ Cold Spring Harbor Laboratory, Cold Spring Harbor, New York 11724 USA
}

\begin{abstract}
A new gene, SCH9, was isolated from Saccharomyces cerevisiae by its ability to complement a $c d c 25^{\text {ts }}$ mutation. Sequence analysis indicates that it encodes a 90,000-dalton protein with a carboxy-terminal domain homologous to yeast and mammalian cAMP-dependent protein kinase catalytic subunits. In addition to suppressing loss of $\mathrm{CDC} 25$ function, multicopy plasmids containing $\mathrm{SCH} 9$ suppress the growth defects of strains lacking the RAS genes, the CYR1 gene, which encodes adenylyl cyclase, and the TPK genes, which encode the CAMP-dependent protein kinase catalytic subunits. Cells lacking $S C H 9$ grow slowly and have a prolonged $G_{1}$ phase of the cell cycle. This defect is suppressed by activation of the cAMP effector pathway. We propose that $\mathrm{SCH} 9$ encodes a protein kinase that is part of a growth control pathway which is at least partially redundant with the cAMP pathway.
\end{abstract}

[Key Words: cAMP; growth control; Saccharomyces cerevisiae]

Received February 8, 1988; revised version accepted April 4, 1988.

In the yeast Saccharomyces cerevisiae the cAMP effector pathway may play an important role in growth regulation. Two of the previously identified temperature-sensitive cell-division-cycle 'start' mutants, cdc25 ts and $c d c 35^{t s}$, which cause $\mathrm{G}_{1}$ arrest at the nonpermissive temperature, block production of cAMP (Matsumoto et al. 1984; Camonis et al. 1986; Martegani et al. 1986b). $C D C 35$ is the same as CYR1, the gene encoding adenylyl cyclase (Boutelet et al. 1985). CDC25 encodes a protein that regulates adenylyl cyclase activity, probably through control of the RAS proteins (Broek et al. 1987; Robinson et al. 1987). Similarly, mutations of the RAS genes, which control the adenylyl cyclase activity of yeast, produce abnormalities of growth control (Kataoka et al. 1985b; Toda et al. 1985; Marshall et al. 1987). We and others have cloned CDC25 by complementation screening (Camonis et al. 1986; Martegani et al. 1986b; Broek et al. 1987; Robinson et al. 1987), and in the process we also isolated the TPK genes, which encode the cAMP-dependent protein kinase (cAPK) catalytic subunits (Toda et al. 1987a). We report here another gene, provisionally called $S C H 9$, that is also capable of suppressing the growth arrest of $c d c 25^{t s}$ when present on

${ }^{1}$ Present address: Department of Biophysics, Faculty of Science, Kyoto University, Kyoto 606, Japan.

${ }^{2}$ Present address: Lederle Labortory, Pearl River, New York 10965 USA. ${ }^{3}$ Corresponding author. multicopy plasmids. SCH9 encodes a protein with a domain most homologous to the catalytic subunits of the cAPK, the cGMP-dependent protein kinase (cGPK), and protein kinase $C$. Like the latter two protein kinases, the SCH9 protein has a large amino-terminal domain. We also describe genetic experiments that examine the interaction of the $S C H 9$ product with the members of cAMP pathway. Overexpression of $S C H 9$ suppresses the growth defects that result from loss of CDC25, both RAS genes, CYR1, or all three TPK genes. Like cells overexpressing components of the cAMP pathway, cells overexpressing $\mathrm{SCH} 9$ are sensitive to heat shock. SCH9 is not itself an essential gene, but $\operatorname{sch} 9^{-}$cells grow slowly. This phenotype is suppressed by activation of the CAMP pathway. Based on these results, we propose that SCH9 encodes an effector kinase for a growth regulatory pathway, which is, to a large extent, redundant with the cAMP pathway.

\section{Results}

\section{Isolation of the $\mathrm{SCH} 9$ gene}

We transformed a temperature-sensitive cdc25 strain, TT25-6 (see Table 1), with pooled DNA from a $S$. cerevisiae genomic library that had been constructed in YEp213 (Sherman et al. 1986; Toda et al. 1987a). Trans- 
Table 1. Strain description

\begin{tabular}{|c|c|c|}
\hline Strain & Genotype and derivation & \\
\hline TT25-6 & Mat $\alpha$ leu2 ura3 trp1 can1 cdc25-1 & Broek et al. (1987) \\
\hline SP1 & Mata his3 leu2 ura3 trp1 ade8 can1 & $\begin{array}{l}\text { Cold Spring Harbor Laboratory } \\
\text { collection }\end{array}$ \\
\hline $\mathrm{DC} 124$ & Mata his4 leu2 ura3 trp1 ade8 can1 & $\begin{array}{l}\text { Cold Spring Harbor Laboratory } \\
\text { collection }\end{array}$ \\
\hline TTSD 1 & A diploid strain formed by mating SP1 and DC124 & Broek et al. (1987) \\
\hline TT1A-1 & $\begin{array}{l}\text { Mato his3 leu2 ura3 trp1 ade8 cdc25::URA3, containing } \\
\text { pCDC25(TRP1)-1 }\end{array}$ & Broek et al. (1987) \\
\hline KPPK-1 & $\begin{array}{l}\text { Mata/Mata his3/his3 leu2/leu2 ura3/ura3 trp1/trp1 ade8/ + can1/+ } \\
\text { ras1::HIS3/ + ras2::URA3/+ }\end{array}$ & Toda et al. (1985) \\
\hline KPPK-1T & A transformant of KPPK-1 with $\mathrm{p} T P K 1-T R P 1$ & \\
\hline SPK-3T & $\begin{array}{l}\text { Mata his3 leu2 ura3 trp1 ade8 can1 ras1::HIS3 ras2::URA3, containing } \\
\text { pTPK1-TRP1 }\end{array}$ & A segregant of tetrads from KPPK-1T \\
\hline $\mathrm{T} 158$ & $\begin{array}{l}\text { Mata/Mata his } 3 /+ \text { his } 4 /+ \text { leu2/leu2 ura3/ura3 trp1/trp1 ade8/ade8 } \\
\text { can1/ + cyr1::URA3/+ }\end{array}$ & $\begin{array}{l}\text { Transformant of TTSD } 1 \text { with } 2.3^{-} \\
\mathrm{kb} B g \text { III fragment of pcyr } 1:: U R A 3^{\mathrm{a}}\end{array}$ \\
\hline $\mathrm{T} 158-\mathrm{T}$ & A transformant of T158 with pTPK1-TRP1 & \\
\hline T158-5AT & Mata his3 leu2 ura3 trp1 ade8 cyr1::URA3 containing pTPK1-TRP1 & A segregant of tetrads from $\mathrm{T} 158-\mathrm{T}$ \\
\hline T168 & $\begin{array}{l}\text { MATa/Mata his3/his3 leu2/leu2 ura3/ura3 trp1/trp1 ade8/ade8 } \\
\text { tpk1::URA3/+ tpk2::HIS3/ + tpk3::TRP1/+ }\end{array}$ & Toda et al. (1987a) \\
\hline T168-T & A transformant of T168 with YRpTPK1-ADE8 & \\
\hline T168-6BT & $\begin{array}{l}\text { Mata his3 leu2 ura3 trp1 ade8 tpk1::URA3 tpk2::HIS3 tpk3::TRP1 } \\
\text { containing pTPK1-ADE8 }\end{array}$ & A segregant from tetrads of $\mathrm{T} 168-\mathrm{T}$ \\
\hline T198 & $\begin{array}{l}\text { Mata/Mat } \alpha \text { his3/ + his4/ + leu2/leu2 ura3/ura3 trp1/trp1 ade8/ade8 } \\
\text { can1/ + sch9::ADE8/ + }\end{array}$ & $\begin{array}{l}\text { A transformant of TTSD } 1 \text { with the } \\
\text { PvuII fragment of psch } 9:: A D E 8\end{array}$ \\
\hline T198-8B & Mata his3 leu2 ura3 trp1 ade8 sch9::ADE8 & A segregant from tetrads of $\mathrm{T} 198$ \\
\hline TT152 & Mata his3 leu2 ura3 trp1 ade8 & A segregant from tetrads of TTSD 1 \\
\hline $\mathrm{T} 213$ & $\begin{array}{l}\text { MATa/ } \alpha \text { his3/his3 leu2/leu2 ura3/ura3 trp1/trp1 ade8/ade8 } \\
\text { sch9::ADE8/+ }\end{array}$ & $\begin{array}{l}\text { A diploid strain formed by crossing } \\
\text { T198-8B and TT } 152\end{array}$ \\
\hline T213-4A & Mata his3 leu2 ura3 trp1 ade8 sch9::ADE8 & A segregant from tetrads of $\mathrm{T} 213$ \\
\hline S13-3A & MAT $\alpha$ his3 leu2 ura3 trp1 ade8 tpk2::HIS3 tpk3::TRP1 byc1::LEU2 & S. Cameron et al. (in prep.) \\
\hline S25 & $\begin{array}{l}\text { MATa/MATa his3/his3 leu2/leu2 ura3/ura3 trp1/trp1 ade8/ade8 } \\
\text { tpk2::HIS3/ + tpk3::TRP1/ + bcy1::LEU2/+ sch9::ADE8/+ }\end{array}$ & $\begin{array}{l}\text { Diploid strain formed by crossing } \\
\text { T198-8B and S13-3A }\end{array}$ \\
\hline $\mathrm{S} 25-31 \mathrm{C}$ & $\begin{array}{l}\text { MATa his3 leu2 ura3 trp1 ade8 tpk2::HIS3 tpk3::TRP1 bcy1::LEU2 } \\
\text { sch9::ADE8 }\end{array}$ & Segregant from diploid strain S25 \\
\hline
\end{tabular}

formants growing at $35^{\circ} \mathrm{C}$ were picked, and their plasmids were transferred to Escherichia coli and mapped for restriction endonuclease sites. Nine different plasmids were isolated. Five of these nine contained known genes: Three plasmids contained TPK1, which is one of the three genes that encode the catalytic subunits of the cAPK (Toda et al. 1987a); one contained CDC25 itself (Camonis et al. 1986; Martegani et al. 1986b; Broek et al. 1987; Robinson et al. 1987); and the other contained CYR1, which encodes adenylyl cyclase (Kataoka et al. 1985a). From restriction mapping and Southern hybridization data, the remaining four plasmids did not contain CDC25, RAS1, RAS2, CYR1, $T P K 1, T P K 2$, or $T P K 3$, all genes capable of suppressing $c d c 25^{\text {ts }}$ when they are carried on multicopy yeast plasmids. Two of the four remaining plasmids contained overlapping restriction fragments and represented a common locus (Fig. 1). We designated the gene of this locus as SCH9 and describe its characterization here. The other two plasmids contain two new genes, which we have provisionally named SCH1 and SCH2. These are currently under study in our lab and are not described here.
The SCH9-gene product has homology to protein kinases

To locate the coding region of $\mathrm{SCH} 9$, various restriction fragments were isolated and subcloned into the yeast shuttle vector, YEp213 (Sherman et al. 1986). These plasmids were transformed into the $c d c 25^{\text {ts }}$ strain TT25-6 (see Table 1) and examined for complementing activity (Fig. 1). The 6.5-kb HindIII fragment was shown to be capable of suppressing $c d c 25^{\text {ts }}$, but the $3.0-\mathrm{kb}$ PvuII fragment was not (Fig. 1). This information provided us with two restriction endonuclease sites from which we began nucleotide sequencing. One long open reading frame was found in this region (Fig. 2). If the first methionine in the open reading frame is used, the $\mathrm{SCH}$ gene would encode a protein of 824 amino acid residues. An in-frame stop codon appears 48 nucleotides upstream from that ATG. Disruption of this open reading frame destroys the activity of the $S C H 9$ gene /data not presented).

The deduced amino acid sequence of the SCH9 gene contains consensus sequences found in all of the known protein kinases (Hunter and Cooper 1986). The sequence Gly X Gly X X Gly (where X is any amino acid), followed 


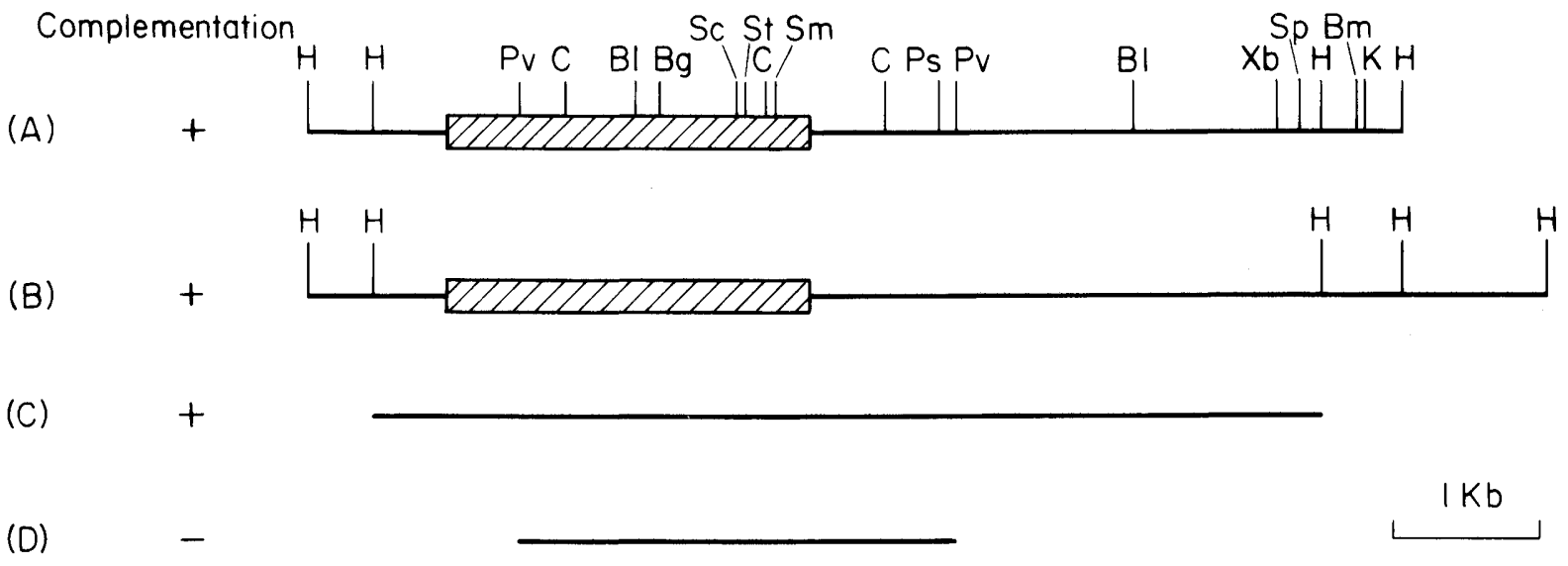

Figure 1. Restriction map and subcloning analysis of the $S C H 9$ locus. Structure and subcloning results of the $S C H 9$ locus are shown. $(A$ and $B)$ Two original suppressor plasmids of $c d c 25^{\text {ts }}$. The $6.5-\mathrm{kb}$ HindIII fragment $(C)$ or the 3.0 -kb PvuII fragment $(D)$ was inserted in the corresponding site of YEp213 (Sherman et al. 1986). The resultant subclones were transformed into the $c d c 25^{\text {ts }}$ strain TT25-6 (see Table 1), and the suppression of temperature sensitivity was examined. Coding sequences for the $S \mathrm{CH} 9$ gene are indicated by hatching. The direction of transcription is from the left to the right. Abbreviations used are as follows: (Bg) BglII; (Bl) BalI; (Bm) BamHI; (C) ClaI; (H) HindIII; (K) KpnI; (Ps) Pst I (Pv) PvuII; (Sc) SacI; (Sm) SmaI; (Sp) SphI; (St) StuI; (Xb) XbaI.

$7-16$ residues later by Lys, is thought to be part of the ATP-binding site (Zoller et al. 1981; Kamps et al. 1984; Hannink and Donoghue 1985). It is shown with inverted triangles in Figure 2. Downstream of the ATP-binding site, two other protein kinase consensus sequences are found: Asp Phe Gly, shown with closed circles in Figure 2; and Ala Pro Glu, shown with open circles in Figure 2. The sequence of the $S \mathrm{CH}$ 9-gene product was used in a computer search of GenBank and the NBRF (PIR) data base. As expected, significant homology was found between $\mathrm{SCH} 9$ and the entire family of protein kinases. The $S C H 9$ protein was most homologous to the catalytic subunits of the cAMP-dependent protein kinases from both yeast and mammals (see Table 2; Fig. 3). In fact, the putative catalytic domain of $S C H 9$ is closer to the cAPK catalytic domains than any other protein $\mathrm{ki}$ nase we have encountered. Homologies with other protein kinases were also apparent. The $\mathrm{SCH} 9$ protein has lower but very significant homology to the catalytic domains of protein kinase $\mathrm{C}$ and $\mathrm{CGPK}$. The $\mathrm{SCH} 9$ protein shows less homology to various other protein kinases. An alignment of the putative catalytic domain of $\mathrm{SCH} 9$ with that of the bovine and yeast cAPKs is seen in Figure 3.

Based on these results, we presume that $S C H 9$ encodes a protein kinase. Like protein kinase $\mathrm{C}$ and $\mathrm{CGPK}$, the $S \mathrm{CH} 9$ protein has a large amino-terminal domain. We presume that this domain is regulatory, but we can find no homology between it and the regulatory domains of other protein kinases.

\section{Disruptions of the cAMP pathway are suppressed by $\mathrm{SCH} 9$ carried on a multicopy plasmid}

A multicopy plasmid carrying the $S C H 9$ gene can suppress a temperature-sensitive $c d c 25$ allele, as can other multicopy plasmids expressing components of the cAMP pathway. To better understand the relationship of the $S C H 9$-gene product to the cAMP pathway, we tested the ability of a multicopy plasmid carrying $S \mathrm{CH} 9$ to suppress other mutations of the cAMP pathway. For this purpose, we used the plasmid exchange method (Broek et al. 1987). Strains were constructed that lacked $C D C 25$ (TT1A-1), both RAS1 and RAS2 genes (SPK-3T), the CYR1 gene (T158-5AT), or all three TPK genes (T168$6 \mathrm{BT})$. The strains were viable because they contained suppressor genes on a multicopy plasmid: $C D C 25$ as the suppressor gene for strain TT1A-1 and TPK1 as the suppressor gene for strains SPK-3T, T158-5AT, and T168-6BT. The construction of these strains is described in Materials and methods. We then tested the ability of a multicopy plasmid containing the $S \mathrm{CH} 9$ gene to replace, or 'exchange,' for the resident suppressor plasmid. The results are shown in Table 3 . The multicopy plasmid containing the $\mathrm{SCH} 9$ gene could exchange for the resident suppressor plasmid in all cases. Overexpression of the $\mathrm{SCH} 9$-gene product therefore appears to compensate for disruption of all the components of the cAMP effector pathway we tested.

\section{Cells that overexpress SCH9 are heat shock sensitive}

Cells with mutations that activate the cAMP pathway are abnormally sensitive to a heat shock (Sass et al. 1986; Broek et al. 1987; Nikawa et al. 1987b; Toda et al. 1987a). The above experiments suggest that the SCH9gene product has functions that overlap those of the yeast CAMP pathway. We therefore asked whether overexpression of $S \mathrm{CH} 9$ results in a heat-shock-sensitive phenotype. For this purpose, we constructed a plasmid, YEp $A D H$-SCH9, in which the $S C H$ 9-coding sequences were under the control of the strong alcohol dehydrogenase I gene promoter (for details, see Materials and methods). This plasmid also contains the LEU2 gene. Leu2- cells were transformed with YEPADH-SCH9, and independent transformants were tested for their ability 
-476 TTTCGTTTGTTGCTTMUGGGTGGATCGGTCATTTACGATMCGGTTCTTTCTGCATATTCCGATCCTTAMGGCTTACTTATTCACATTACGGGTCCAMTATMACATAGATTGTTGTG -357 CTCAGCTCATCCATTTCGCTGGTCGCTTATATTCTCTTTTTTGTTTTATTCTTTTCTTTCCTTCAAGTTCTTTGCAACAGCACTGAMATAGTTACAMCMACTTTGCGCCAGTTCCC -238 GCCTCCTTATTCTTTTTCCAGCTCTCTTCTACTTTCTTTTTTGTTTTATTCTTTTCTTTCCTTCAAGGTTCTTTGCACAGCACTGAMATAGTTACAMCAMCTTTGCGCCAGTTCCC

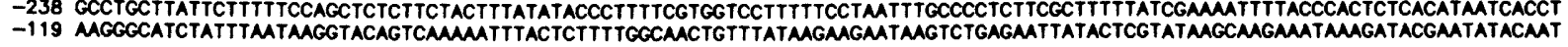

1 MET MET ASN PHE PHE THR SER LYS SER SER ASN GLN ASP THR GLY PHE SER SER GLN HIS GLN HIS PRO ASN GLY GLN ASN ASN GLY ASN 1 ATG ATG MAT TTT TTT ACA TCA MM TCG TCG AMT CAG GAT ACT GGA TTT AGC TCT CAA CAC CMA CAT CCA MT GGA CAG MAC MAT GGA MAC 31 ASN ASN SER SER THR ALA GLY ASN ASP ASN GLY TYR PRO CYS LYS LEU VAL SER SER GLY PRO CYS ALA SER SER ASN ASN GLY ALA LEU 91 MT MT AGC AGC ACC GCT GGC MAC GAC MAC GGA TAC CCA TGT MM CTG GTG TCC AGT GGG CCC TGC GCT TCA TCA MAT MAT GGT GCC CTT 61 PHE THR ASN PHE THR LEU GLN THR ALA THR PRO THR THR ALA ILE SER GLN ASP LEU TYR ALA MET GLY THR THR GLY ILE THR SER GLU 181 TTT ACG MT TTT ACT TTA CM ACT GCA ACG CCG ACC ACC GCT ATT AGT CAG GAC TTA TAT GCA ATG GGC ACA ACA GGA ATA ACA TCA GM 91 ASN ALA LEU PHE GLN MET LYS SER MET ASN ASN GLY ILE SER SER VAL ASN ASN ASN ASN SER ASN THR PRO THR ILE ILE THR THR SER 271 MAT GCC CTT TTT CMA ATG MGG TCA ATG MAT MAT GGA ATA TCA TCA GTT MTT MAT MC MC AGC MAC ACC CCT ACG ATT ATT ACC ACG TCA 121 GLN GLU GLU THR ASN ALA GLY ASN VAL HIS GLY ASP THR GLY GLY ASN SER LEU GLN ASN SER GLU ASP ASP ASN PHE SER SER SER SER 361 CAG GAM GM ACT MAT GCT GGA MMT GTA CAT GGC GAT ACC GGT GGC MAT TCT TTG CAM MT TCT GA GAT GAC MMC TTT TCT TCC AGT TCT 151 THR THR LYS CYS LEU LEU SER SER THR SER SER LEU SER ILE ASN GLN ARG GLU ALA ALA ALA ALA ALA TYR GLY PRO ASP THR ASP ILE 451 ACC ACC MA TGC TTA CTC TCT TCC ACT TCT TCG CTA TCA ATA MMT CA CGA GM GCA GCA GCA GCT GCT TAT GGT CCA GAT ACC GAT ATT 181 PRO ARG GLY LYS LEU GLU VAL THR ILE ILE GLU ALA ARG ASP LEU VAL THR ARG SER LYS ASP SER GLN PRO TYR VAL VAL CYS THR PHE 541 CCT AGG GGT MA CTA GA GTT ACA ATA ATA GM GCA CGT GAC CTA GTC ACT AGA TCA MM GAT TCA CAG CCT TAT GTT GTT TGT ACT TTT 211 GLU SER SER GLU PHE ILE SER ASN GLY PRO GLU SER LEU GLY ALA ILE ASN ASN ASN ASN ASN ASN ASN ASN ASN ASN GLN HIS ASN GLN 631 GAG AGT TCA GAG TTC ATT TCT MAT GGT CCT GAG TCA CTA GGC GCC ATT MMT MAT MAC MC MAT MC AMC MC MUT MAT CAG CAT MMT CAA 241 ASN GLN HIS ILE ASN ASN ASN ASN GLU ASN THR ASN PRO ASP ALA ALA SER GLN HIS HIS ASN ASN ASN SER GLY TRP ASN GLY SER GLN 721 AMC CAG CAT ATT AMC MC MC MC GM MT ACC MC CCT GAC GCT GCT AGC CAG CAT CAT MMT MAT AMC AGT GGT TGG MMC GGT TCT CAG 271 LEU PRO SER ILE LYS GLU HIS LEU LYS LYS LYS PRO LEU TYR THR HIS ARG SER SER SER GLN LEU ASP GLN LEU ASN SER CYS SER SER 811 TTA CCA TCG ATA MA GAG CAC TTG MG MA MA CCC CTT TAT ACA CAC AGA TCA TCT TCC CAM TTA GAT CAG CTA MAC TCT TGC TCT TCA

301 VAL THR ASP PRO SER LYS ARG SER SER ASN SER SER SER GLY SER SER ASN GLY PRO LYS ASN ASP SER SER HIS PRO ILE TRP HIS HIS 901 GTA ACC GAT CCG AGC MM CGT TCT TCT MAT TCT TCG TCG GGT TCT TCA MT GGT CCA MA MT GAT AGT TCA CAT CCA ATA TGG CAT CAC 331 LYS THR THR PHE ASP VAL LEU GLY SER HIS SER GLU LEU ASP ILE SER VAL TYR ASP ALA ALA HIS ASP HIS MET PHE LEU GLY GLN VAL 991 AAG ACA ACG TTT GAT GTT TTG GGA TCT CAC TCG GM TTA GAT ATT TCT GTT TAT GAT GCT GCC CAC GAC CAT ATG TTC TTA GGC CAM GTT 361 ARG LEU TYR PRO MET SER HIS ASN LEU ALA HIS ALA SER GLN HIS GLN TRP HIS SER LEU LYS PRO ARG VAL ILE ASP GLU VAL VAL SER 1081 AGA CTG TAT CCA ATG AGT CAT MAT TTA GCA CAT GCT TCC CAM CAC CAA TGG CAC AGT TTG MA CCT CGC GTT ATT GAT GAA GTT GTG TCC 391 GLY ASP ILE LEU ILE LYS TRP THR TYR LYS GLN THR LYS LYS ARG HIS TYR GLY PRO GLN ASP PHE GLU VAL LEU ARG LEU LEU GLY LYS 1171 GGT GAT ATT TTA ATC AMA TGG ACT TAC AMA CAG ACA AAG AMA AGA CAT TAT GGC CCA CAA GAT TTT GAA GTT CTT CGA TTA TTG GGT AAG 421 GLY THR PHE GLY GLN VAL TYR GLN VAL LYS LYS LYS ASP THR GLN ARG ILE TYR ALA MET LYS VAL LEU SER LYS LYS VAL ILE VAL LYS 1261 GGT ACT TTT GGC CAA GTC TAC CAA GTT AAG AAG AMA GAC ACT CAA AGA ATT TAT GCA ATG AMA GTT CTC TCC AAG AMA GTT ATT GTC MAG 451 LYS ASN GLU ILE ALA HIS THR ILE GLY GLU ARG ASN ILE LEU VAL THR THR ALA SER LYS SER SER PRO PHE ILE VAL GLY LEU LYS PHE 481 SER PHE GLN THR PRO THR ASP LEU TYR LEU VAL THR ASP TYR MET SER GLY GLY GLU LEU PHE TRP HIS LEU GLN LYS GLU GLY ARG PHE 1441 TCC TTT CM ACA CCA ACA GAT CTG TAT TTG GTC ACT GAT TAT ATG AGT GGT GGA GM TTA TTC TGG CAT TTA CMA MAG GAG GGC CGT TTT

511 SER GLU ASP ARG ALA LYS PHE TYR ILE ALA GLU LEU VAL LEU ALA LEU GLU HIS LEU HIS ASP ASN ASP ILE VAL TYR ARG ASP LEU LYS 1531 TCG GM GAC AGA GCG AAA TTC TAT ATC GCT GAG ITA GTC CTA GCG TTA GM CAT TTA CAC GAT MAC GAT ATC GTT TAC AGG GAC CTA MG 541 PRO GLU ASN ILE LEU LEU ASP ALA ASN GLY ASN ILE ALA LEU CYS ASP PHE GLY LEU SER LYS ALA ASP LEU LYS ASP ARG THR ASN THR 541 PRO GLU ASN ILE LEU LEU ASP ALA ASN GLY ASN ILE ALA LEU CYS ASP PHE GLY LEU SER LYS ALA ASP LEU LYS ASP ARG THR ASN THR
1621 CCT GM MC ATT CTA CTC GAT GCC MAC GGT MC ATC GCT CTT TGC GAT TTT GGT CTT TCT MA GCT GAC TTG MAG GAT AGA ACA MC ACA 571 PHE CYS GLY THR THR GLU TYR LEU ALA PRO GLU LEU LEU LEU ASP GLU THR GLY TYR THR LYS MET VAL ASP PHE TRP SER LEU GLY VAL 1711 TTT TGC GGC ACC ACG GM TAC CTG GCA CCA GAA TTG TTA CTG GAC GM ACC GGC TAC ACC AMA ATG GTC GAT TTC TGG TCT CTA GGT GTT 601 LEU ILE PHE GLU MET CYS CYS GLY TRP SER PRO PHE PHE ALA GLU ASN ASN GLN LYS MET TYR GLN LYS ILE ALA PHE GLY LYS VAL LYS 1801 TTG ATA TTT GAM ATG TGT TGT GGT TGG TCC CCT TTC TTT GCG GM MAT MAT CAM MM ATG TAC CAM MMA ATT GCC TTT GGT MMA GTC AMA 631 PHE PRO ARG ASP VAL LEU SER GLN GLU GLY ARG SER PHE VAL LYS GLY LEU LEU ASN ARG ASN PRO LYS HIS ARG LEU GLY ALA ILE ASP 661 ASP GLY ARG GLU LEU ARG ALA HIS PRO PHE PHE ALA ASP ILE ASP TRP GLU ALA LEU LYS GLN LYS LYS ILE PRO PRO PRO PHE LYS PRO 1981 GAT GGA AGA GAA CTA CGA GCT CAT CCA TTT TTC GCA GAT ATC GAC TGG GAG GCC TTG MG CAG MM MMA ATT CCA CCA CCT TTC MMA CCT 691 HIS LEU VAL SER GLU THR ASP THR SER ASN PHE ASP PRO GLU PHE THR THR ALA SER THR SER TYR MET ASN LYS HIS GLN PRO MET MET 2071 CAC CTA GTC TCG GAG ACG GAT ACC TCG MT TTT GAC CCA GAG TTC ACA ACA GCT TCA ACT TCA TAC ATG MAC MG CAC CAG CCG ATG ATG 721 THR ALA THR PRO LEU SER PRO ALA MET GLN ALA LYS PHE ALA GLY PHE THR PHE VAL ASP GLU SER ALA ILE ASP GLU HIS VAL ASN ASN 2161 ACT GCT ACC CCG CTA TCT CCA GCC ATG CM GCA MG TTT GCT GGT TTC ACC TTT GTT GAT GAG TCC GCC ATC GAT GM CAC GTT MT MAC 751 LYS ARG LYS PHE LEU GLN ASN SER TYR PHE MET GLU PRO GLY SER PHE ILE PRO GLY ASN PRO ASN LEU PRO PRO ASP GLU ASP VAL ILE 2251 MG AGA MA TTC CTA CM AMC TCG TAC TTT ATG GA CCT GGT TCC TTT ATC CCG GGA MAT CCA MA TTA CCT CCA GAC GMA GAT GTC ATC 781 ASP ASP ASP GLY ASP GLU ASP ILE ASN ASP GLY PHE ASN GLN GLU LYS ASN MET ASN ASN SER HIS SER GLN MET ASP PHE ASP GLY ASP 2341 GAT GAT GAC GGG GAC GAG GAC ATC MMT GAT GGA TTC MAC CAM GAG MM MAT ATG AMC MA AGC CAT TCG CAG ATG GAC TTC GAC GGC GAC 811 GLN HIS MET ASP ASP GLU PHE VAL SER GLY ARG PHE GLU ILE *** 2431 CAA CAC ATG GAT GAC GA TTT GTC AGT GGA AGA TTC GMA ATA TGA TTTCTCAATCGCTCCTCTTGCCCTTCCTCTTCTTTTCCTTTTCTTTTTATTTTTTTCTA 2535 ATTTTTCTATCTTTTATTTCTACTTCTATTATTMATTTGTATCTTCTMATCGTTTTTGCCCACTTTATCGAMCATTCTTCTATTTATATATGTMAGTATGTATGTATTTTCGTTTTA

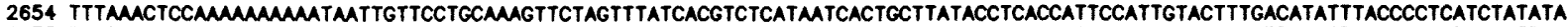
2773 TMTCAGGGCTTMGTAMCGCTTCGCTGTGATTTCCCMUGTCGGTTCGGMUTTATAGGTCGGTTATATCATCCGMUMUMUMUMUMGTTTTTCTTAMTGCATAGGTTTM 2892 AGTCGATTMMGTAGGGCTACACAMGTATMGCAGGGTTTGCTATMTAGGGATGCCATMGTGAGGGCAGGGCTCATCGATGCGCGTACATGGATTTTCCGMATTCTGATTTT 2892 AGTCGATTMMGTAGGGCTACACAAGTATMGCAGGGTTTTGCTATMTAGGGATGCCATMGTGAGGGCAGGGCTCATCGATGCGCGTACATGGATTTTCCGMATTCTGATTTT 3011 TTCTTTCTTTACTATGAGCAMATGTGGTCAGCTTTACTGAGCTTAMCTGTCATCCCATCGMTGTGACAGATTGMAGTGCTTCCAGGATCTGMACAMTTGTCAMGTTTTACTA 3130 ACATTACACAGATATCCCTGGTCACCTTACTATCTTCCACATCTTACCTAGGCTTGCTGCTTTTGTTTGGGTCATATATTTAACTCGCTCATTAGAGGACATTCTGTTTTTTCCAAGA

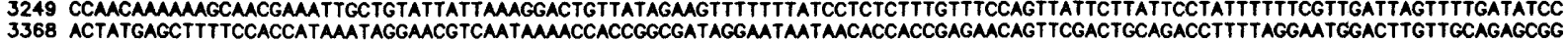

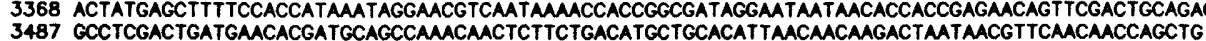

Figure 2. (See facing page for legend.) 
Table 2. Protein kinases homologous to $\mathrm{SCH} 9$

\begin{tabular}{lcl}
\hline Protein kinase & Score & \multicolumn{1}{c}{ Source } \\
\hline Yeast cAPK (TPK1) & 41 & Lisziewicz et al. (1987) \\
Bovine cAPK & 39 & Shoji et al. (1981) \\
Bovine cGPK & 34 & Takio et al. (1984) \\
Rat protein kinase & 32 & Knopf et al. (1986) \\
$\quad$ C-type I & & \\
Rabbit muscle & 30 & Reimann et al. (1984) \\
$\quad$ phosphorylase & & \\
$\quad$ b kinase & & Teague et al. (1986) \\
Yeast STE7 & 18 & Lorincz et al. (1983) \\
Yeast CDC28 & 14 &
\end{tabular}

Alignment scores (see Materials and methods for details) for eight protein kinases are presented. Higher scores indicate greater similarity to $\mathrm{SCH}$ 9. The average alignment score when $S C H 9$ was compared with 31 different protein kinases was 13 with a S.D. of 12 .

to withstand a heat shock treatment. The results (Fig. 4) clearly indicate that overexpression of the SCH9 gene leads to heat shock sensitivity.

\section{Cells with disrupted SCH9 grow slowly}

To examine the effect on cells of perturbing the SCH9 gene, one-step gene disruption (Rothstein 1983) was carried out. An SCH9 disruption plasmid was constructed by inserting the $3.4-\mathrm{kb} B a m H I / B g l I I ~ A D E 8$ marker (White et al. 1985) into the BglII site, which is located in the middle of the $S C H$ 9-coding sequence (see Fig. 1 ; Materials and methods). Insertion of $A D E 8$ into the SCH9 at this coding sequence site causes an interruption at the $487^{\text {th }}$ amino acid. This separates the consensus ATP- binding sequence, Gly X Gly X X Gly, from the consensus sequence Asp Phe Gly. Both of these regions are thought to be important for kinase activity, and, therefore, we would predict that a disruption in that region would inactivate the SCH9 protein. An sch $9:: A D E 8$ fragment was used to transform the diploid TTSD 1 (Table 1). One resultant transformant, T198, was sporulated, and tetrad dissection carried out. As shown in Figure 5, two normal-sized colonies and two small colonies were obtained in nearly all the tetrads. A test for auxotrophic markers showed that the normal-sized colonies were always $\mathrm{Ade}^{-}$and the small colonies were $\mathrm{Ade}^{+}$. Genomic Southern hybridization of the haploid segregants derived from T198 showed that the SCH9 gene was indeed disrupted in $\mathrm{Ade}^{+}$cells (data not shown). This result indicates that disruption of the SCH9 gene is not lethal but that cells without SCH9 have a growth disadvantage. The doubling time of the sch $9^{-}$cells was about two times longer than that of wild type-cells (Table 4). The proportion of unbudded cells was measured during exponential growth, and from this we calculated (Rivin and Fangmann 1980) that the increase in the doubling time was due entirely to an increase in the duration of the $G_{1}$ phase of the cell cycle.

Small colony size of sch9- is suppressed by activation of the $C A M P$ pathway

Next, we determined whether activation of the cAMP pathway could compensate for the growth defects observed in sch9- cells. The regulatory subunit of the cAPK, encoded by the $B C Y 1$ gene, is responsible for controlling the activity of the cAPK /Matsumoto et al. 1982;

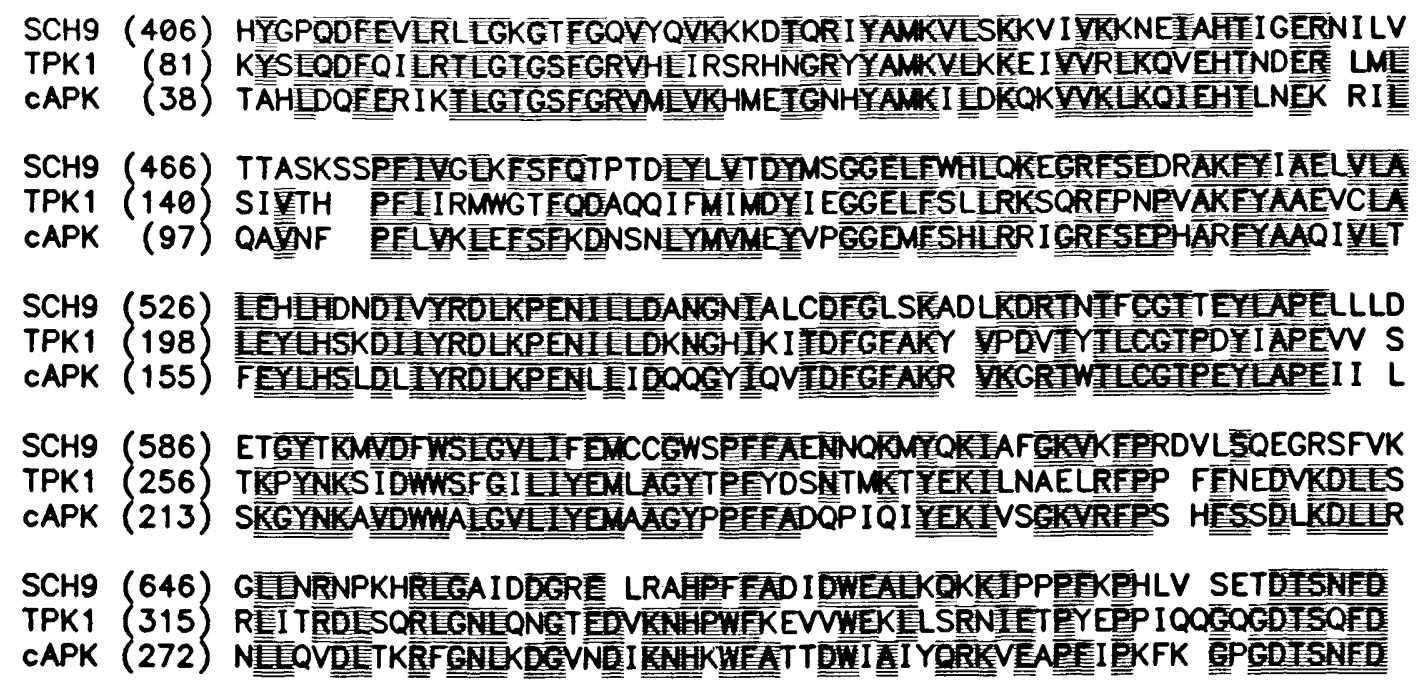

Figure 3. Amino acid sequence comparison between $S C H 9$ and cAPK catalytic subunits. A portion of the amino acid sequence of SCH9 is compared to that of TPK1, one of three yeast genes that encode the catalytic subunits of the cAPK (Toda et al. 1987a), and the bovine C $\alpha$ catalytic subunit (Shoji et al. 1981; Showers and Mauver 1986). Identical amino acids are shadowed.

Figure 2. Nucleotide sequence and deduced amino acid sequence of $S C H 9$. The sequence starts at the HindIII site at -509 bp and continues through the second PvuII site (see Fig. 1). In addition to the deduced amino acid sequence, 4084 nucleotides of $S C H 9$ are shown. ( $)$ The consensus sequence for amino acids at the ATP-binding site. Invariant sequences among known protein kinases are indicated: $\left(\bullet \mid\right.$ Asp Phe Gly; $(0)$ Ala Pro Glu. $\left(^{*}\right)$ The $3^{\prime}$ termination codon. 
Toda et al.

Table 3. The suppression profile of the SCH9 gene carried on a multicopy plasmid

\begin{tabular}{|c|c|c|c|c|}
\hline $\begin{array}{l}\text { Viability of cells } \\
\text { carrying } \\
\text { extrachromosomal }\end{array}$ & & bility of cells & chrome & al genotype \\
\hline high copy gene ${ }^{a}$ & $\overline{c d c 25^{-}}$ & ras1- ras2- & cyr1- & $t p k 1^{-} t p k 2^{-} t p k 3^{-}$ \\
\hline$\phi$ & - & - & - & - \\
\hline$C D C 25$ & + & - & - & NT \\
\hline RAS2 & - & + & - & NT \\
\hline$R A S 2^{\text {Val19 }}$ & + & + & - & NT \\
\hline CYR1 & + & + & + & NT \\
\hline$T P K 1$ & + & + & + & + \\
\hline SCH9 & + & + & + & + \\
\hline
\end{tabular}

Yeast strains were constructed that contain disruptions of chromosomal genes but were viable because they contained known suppressor genes on multicopy plasmids (see Materials and methods). Genes being tested (left-hand column) for suppression of the indicated chromosomal mutations were introduced into these strains on multicopy plasmids, and the ability of one plasmid to replace, or "exchange," for the resident suppressor plasmid was determined (Broek et al. 1987). $1+$ | The exchange could occur, and the specified gene, when present on multicopy plasmid, can suppress the indicated chromosomal mutations. | | The specified multicopy plasmid could not exchange for the resident suppressor plasmid. (NT) Not tested. TT1A-1, SPK-3T, T158-5AT, and T168-6BT were

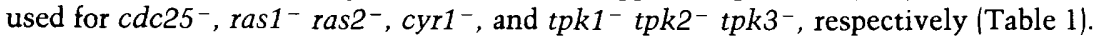

a pCDC25 (LEU2)-2 (Broek et al. 1987), YEpRAS2-1 (Powers et al. 1984), pRAS2val19 (Broek et al. 1987), YEp13-CYR1-11 (Kataoka et al. 1985a), YEpTPK1 (Toda et al. 1987a), and YEpSCH9 (Fig. 1A) were multicopy plasmids containing the indicated genes. The negative control, $\phi$, was the multicopy plasmid YEpl3 (Sherman et al. 1986).

Johnson et al. 1987; Toda et al. 1987b). Disruption of the $B C Y 1$ gene activates the cAPK (Toda et al. 1987b). Therefore, we asked whether disruption of the $B C Y 1$ gene can suppress the sch $9^{-}$growth defect. To this end, a yeast strain, S25-31C, was constructed in which both the $\mathrm{SCH} 9$ and $\mathrm{BCY} 1$ genes were disrupted (for details, see Materials and methods). This strain was then transformed with a multicopy plasmid carrying the $B C Y 1$ gene. Plasmid segregation analysis (Fig. 6) reveals that loss of the $B C Y 1$ gene, with resulting activation of the cAMP pathway, suppresses the small colony size of sch9- cells. Similar experiments with $R A S 2^{\text {valli, }}$, a mutant RAS2 gene that activates the cAMP pathway (Toda et al. 1985), lead to similar conclusions (data not presented).

\section{Discussion}

We have isolated and characterized $\mathrm{SCH}$, a new gene of $S$. cerevisiae. Judging by primary sequence analysis, $S C H 9$ encodes a protein kinase with a catalytic domain that closely resembles the cAPK catalytic domain of bovine or yeast origin. Indeed, the $\mathrm{SCH} 9$ kinase is as related to the bovine CAPK in that domain as is the yeast cAPK. Like protein kinase $\mathrm{C}$ and the $\mathrm{CGPK}$, but unlike the authentic cAPK catalytic subunits, the SCH9-encoded protein has a large amino-terminal domain. Although this domain does not resemble that of the $\mathrm{C} \mathrm{ki-}$ nases or the cGPK, we nevertheless presume that it has a regulatory function.

The similarity between $S C H 9$ and the TPK genes,

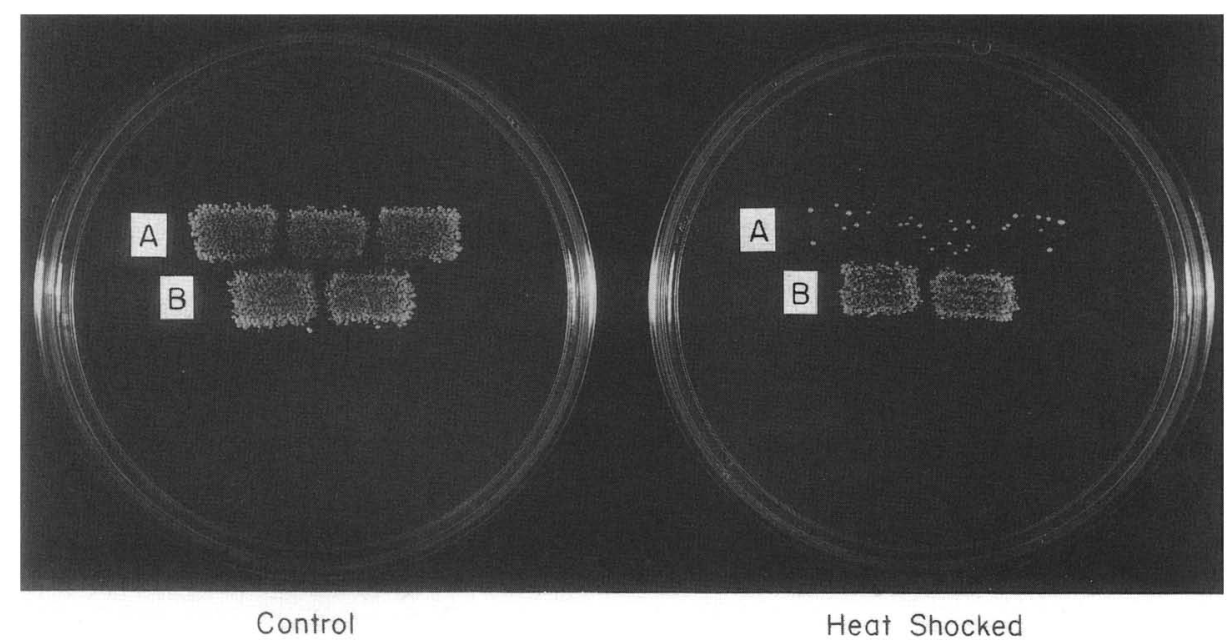

Figure 4. Heat shock sensitivity of cells overexpressing $S C H 9$. The wild-type yeast strain SPl was transformed with a multicopy plasmid carrying $S C H 9$ under the control of the alcohol dehydrogenase I gene promoter $(A)$ or a control plasmid lacking the $S C H 9$ gene (B). Independent transformants were picked, grown on an SC-Leu plate for 2 days, replica plated onto a preheated SC-Leu plate, and incubated at $55^{\circ} \mathrm{C}$ for $45 \mathrm{~min}$. Patches of cells on heat-shocked plates were incubated at $30^{\circ} \mathrm{C}$ for 2 days before being photographed. 


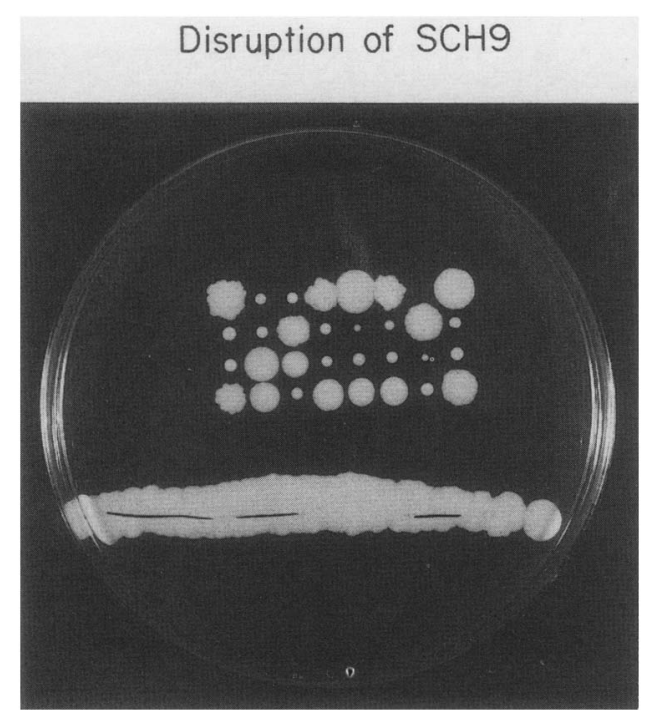

Figure 5. Phenotype of sch $9^{-}$cells. A diploid heterozygous for a disruption of the SCH9 gene, T198 (Table 1), was sporulated and asci dissected. The picture was taken after 5 days of incubation at $30^{\circ} \mathrm{C}$. Vertical rows are spores from single asci.

which encode the yeast cAPK catalytic subunits, extends beyond the primary sequence of their encoded proteins. $\mathrm{SCH} 9$ was isolated as a suppressor of temperaturesensitive alleles of $C D C 25$, a gene required for the maintenance of cAMP levels in yeast. In fact, multicopy plasmids containing $\mathrm{SCH} 9$ can suppress the defects resulting from loss of several of the components of the cAMP pathway. Moreover, overexpression of the $\mathrm{SCH} 9$ gene leads to a phenotype, heat shock sensitivity, seen in cells with an activated cAMP pathway. Conversely, the slow-growth phenotype of cells bearing a disrupted $S C H 9$ gene can be reversed by the activation of the cAMP pathway. These results indicate that the functions of the cAPK and the $S C H 9$ protein kinase could be largely redundant.

We have not formally excluded the unlikely possibility that the $S \mathrm{CH} 9$ gene encodes a highly divergent form of cAPK. We can test this possibility directly once we are able to assay the kinase activity of the $\mathrm{SCH} 9$ protein. It seems more likely that in yeast, as in higher eukaryotes (Rasmussen 1986), physiologic events are controlled by multiple signaling pathways. Recent experiments by our lab strongly support this idea. We have isolated mutant TPK genes, called $t p k^{w}$ alleles, which suppress all of the defects observed in strains lacking the $B C Y 1$ gene (Cameron et al. 1988). bcy $1^{-}$strains containing the $t p k^{\mathrm{w}}$ alleles $\left(b c y 1^{-} \cdot t p k^{\mathrm{w}}\right.$ strains) respond appropriately to changing nutrient conditions (Cameron et al. 1988). Intracellular cAMP levels can be varied over a 10,000 -fold range in the $b c y 1^{-} t p k^{w}$ strains without noticeable phenotypic effects (Nikawa et al. 1987a; Cameron et al. 1988). These results would tend to exclude the possibility that $S \mathrm{CH} 9$ encodes a cAPK. Rather, the experiments suggest that many of the nutrient responses thought to be dependent upon the cAMP effector system may also be under the parallel or redundant control of
Table 4. Growth characteristics of sch9- cells

\begin{tabular}{llllrc}
\hline Strain & $\begin{array}{l}\text { Geno- }^{-} \\
\text {type }^{\mathrm{a}}\end{array}$ & $\begin{array}{l}\text { Doubling } \\
\text { time } \\
(\mathrm{D})^{\mathrm{b}}\end{array}$ & $\begin{array}{l}\text { Fraction } \\
\text { unbudded } \\
(\mathbf{F})^{\mathrm{b}}\end{array}$ & $\mathrm{G}_{1}{ }^{\mathrm{b}}$ & $\mathrm{D}-\mathrm{G}_{1}{ }^{\mathrm{b}}$ \\
\hline SP1 & SCH9 & 114 & 0.43 & 40 & 74 \\
T198-8B & sch9- & 207 & 0.67 & 122 & 85 \\
T213-4A & sch9- & 252 & 0.77 & 176 & 76 \\
\hline
\end{tabular}

a The full genotypes of these strains are described in Table 1.

$\mathrm{b}$ The doubling time (D) of cells incubated in rich YPD medium was measured during exponential growth at $30^{\circ} \mathrm{C}$. The fraction (F) of unbudded cells (cells in $G_{1}$ ) during exponential growth was determined by the microscopic examination of 200 cells. The duration of $G_{1}$ was determined using the formula $G_{1}=D[1$ $-\log (2-F) / \log 2$ ] (Rivin and Fangmann 1980). The difference $\left(D-G_{1}\right)$ represents the duration of the cell cycle, excluding $G_{1}$. Time values are in minutes.

other, cAMP-independent signaling systems. The $\mathrm{SCH} 9$ protein kinase is certainly a candidate component of such a system.

\section{Materials and methods}

Strains, media, genetic procedures, and nomenclature

Yeast strains used in this study are listed in Table 1. E. coli HB101 was used for plasmid construction and purification. Yeast media have been described (Toda et al. 1985). Standard yeast genetic procedures were followed throughout (Sherman et al. 1986). The lithium acetate method was used for transformation of yeast cells (Ito et al. 1983). Heat shock experiments were performed as described (Sass et al. 1986). Gene disruptions are denoted by lowercase letters, followed by two colons, followed by the wild-type prototrophic marker used for disruption. In the text, gene disruptions are often abbreviated by lowercase letters, followed by a superscript minus sign, such as $\operatorname{sch} 9^{-}$. A strain that has a temperature-sensitive recessive mutation is shown by lowercase letters, followed by a superscript ' $t \mathrm{~s}$,' such as $c d c 25^{t s}$.

\section{DNA preparation and manipulation}

Plasmid DNA was isolated from $E$. coli using the alkali-lysis method (Maniatis et al. 1982). Yeast DNA was prepared essentially as described (Nasmyth and Reed 1980). Restriction endonucleases, T4 DNA ligase, and the large fragment of DNA polymerase I were used as recommended by their suppliers (New England Biolabs, Inc., Bethesda Research Labs, Inc., or Boehringer Mannheim Biochemicals). Standard molecular cloning techniques were as described (Maniatis et al. 1982).

\section{Nucleotide sequence determination}

The dideoxy sequence method (Sanger et al. 1977) using [ $\left.\alpha^{-35} S\right]$ dATP as a substrate (Biggin et al. 1983) was carried out in combination with the unidirectional progressive deletion method (Henikoff 1984) using double-stranded plasmid DNA as template (Hattori and Sakaki 1986). A 3.0-kb PvuII fragment (see Fig. 1) was subcloned into the SmaI site of pUC18 (YanischPerron et al. 1985) in both orientations. BamHI and SphI were used subsequently to linearize these plasmids before deletion by ExoIII and ExoVII. A 6.5-kb HindIII fragment (see Fig. 1) was subcloned into the HindIII site of pUC19 (Yanisch-Perron et al. $1985)$ in both orientations. SalI and KpnI were used for linear- 
Toda et al.

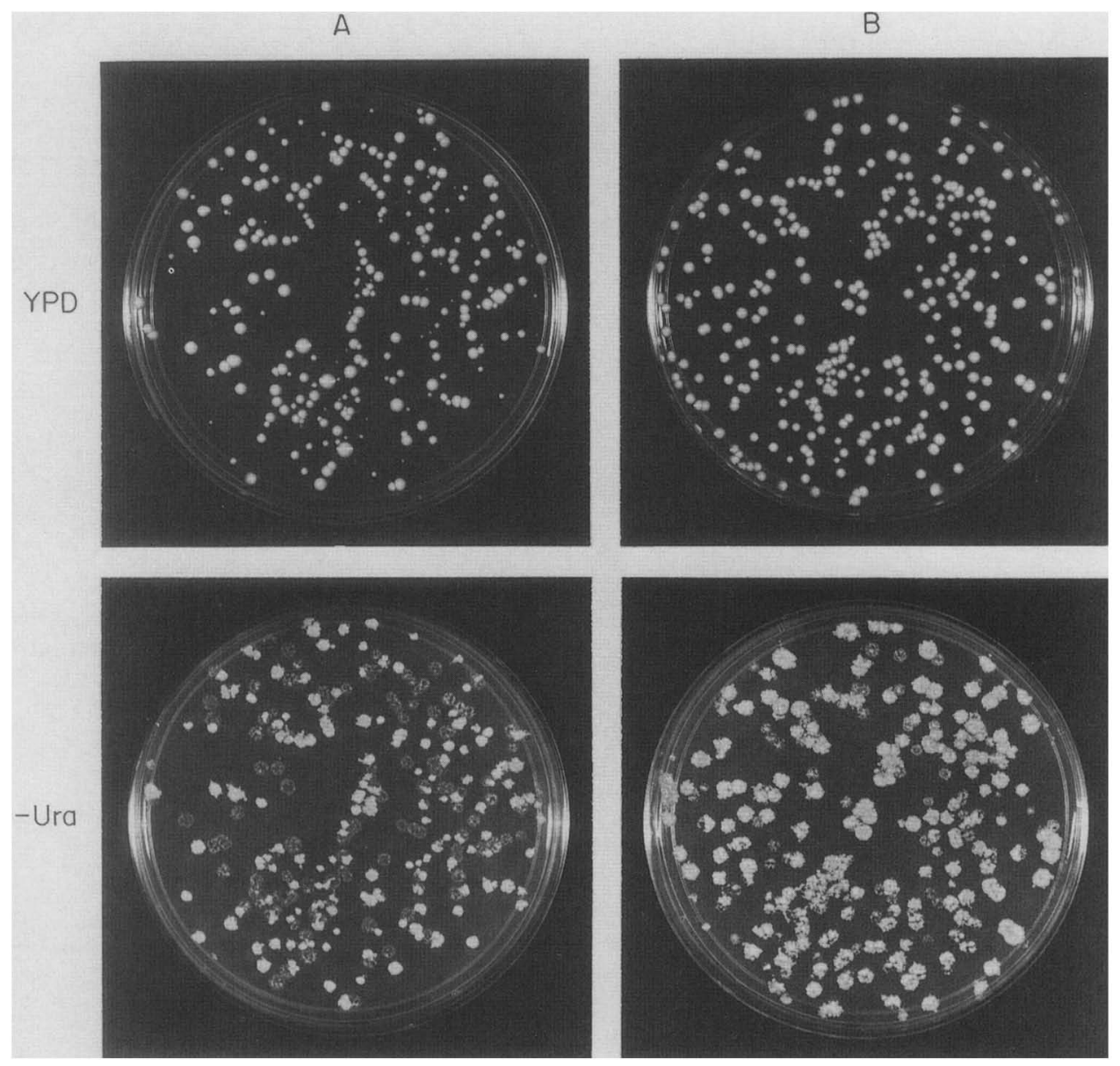

Figure 6. Suppression of the $s c h 9^{-}$growth defect by $b c y 1^{-}$. The strain S25-31C (see Table 1), a ura3- strain that lacks both the $S C H 9$ gene and the gene for the regulatory subunit of the CAPK $(B C Y 1)$, was transformed by multicopy plasmids carrying the $U R A 3$ gene $(B)$ or both the $U R A 3$ and the $B C Y 1$ genes $(A)$. A transformant was grown overnight in YPD medium, diluted, plated onto YPD plates, and grown at $30^{\circ} \mathrm{C}$ for 3 days before being photographed. In the absence of Ura selection, the $B C Y 1$ plasmids were unstable, and some colonies on each YPD plate were formed from cells that had lost their respective plasmid. After being photographed, the YPD plates were replica plated onto SC-Ura plates (which select for $\mathrm{Ura}^{+}$cells) to reveal which colonies were formed from plasmid-containing cells. Colony sizes are distorted by replica plating, but notice that colony sizes in $A$ are very heterogeneous on the master plate. Small colonies on the YPD plate are Ura ${ }^{+}$(i.e., contain $\left.B C Y 1\right)$, and large colonies on the YPD plate are Ura- $\left(\right.$ i.e., are $\left.b c y 1^{-}\right)$. On the other hand colony sizes in $B$ are more uniform on the master plate and are generally large. These cells are all sch $9^{-} b c y 1^{-}$. No consistent size difference is noted in the segregants from the transformant carrying the control plasmid. Multicopy plasmids containing the $B C Y 1$ gene do not affect the growth rate of wild-type strains (data not presented).

izing these plasmids. A total of 4084 nucleotides, from HindIII to the second PvuII site, were sequenced on both strands.

\section{Analysis of protein sequence similarities}

The IFIND program from IntelliGenetics was used to identify and optimally align the $S C H 9$ protein with similar proteins in the NBRF (PIR) protein data base and with translations of nucleic acid sequences in GenBank. The alignment algorithm used by the IFIND program is based on the work of Dumas and Ninio (1982), Needleman and Wunsch (1970), and Wilbur and Lipman (1983). The parameter settings used were window size $=20$, word length $=1$, gap penalty $=2$, fast $=$ yes, and density $=$ less.

\section{Isolation of genes that can suppress a temperature-sensitive $\operatorname{cdc} 25$}

The temperature-sensitive $c d c 25^{\text {ts }}$ strain, TT25-6 (see Table 1), was transformed with a yeast genomic library that was constructed by inserting yeast DNA partially digested with HindIII into YEp213, which contains the LEU2 marker (Sherman et al. 1986; Toda et al. 1987a). Transformants were selected for temperature-sensitive suppression, either by incubating directly at $35^{\circ} \mathrm{C}$ on synthetic plates lacking leucine or by first incubating at room-temperature on plates lacking leucine and then replica-plating onto YPD plates followed by incubation at $35^{\circ} \mathrm{C}$. Colonies that could grow at $35^{\circ} \mathrm{C}$ were picked, and plasmid segregation analysis was performed. Transformants whose growth at $35^{\circ} \mathrm{C}$ was plasmid dependent were chosen, and their plasmids recovered by transforming $E$. coli. Each plasmid was transformed back into TT25-6 to confirm its ability to suppress the temperature-sensitive phenotype.

\section{Yeast strain constructions}

To test whether the SCH9 gene carried on a multicopy plasmid could suppress loss of genes involved in the RAS/cAMP 
pathway, several mutant haploid strains were made. (1) The haploid strain, SPK-3T (see Table 1), is a tetrad segregant from the diploid KPPK-1T. KPPK-1T was derived from the diploid KPPK-1 (Toda et al. 1985) by transformation with pTPK1-TRP1. KPPK-1 is a diploid heterozygous at both of the RAS genes (Toda et al. 1985). pTPK1-TRP1 contains the 2.4-kb HindIII/ SphI fragment of TPK1 (Toda et al. 1987a) and the 1.4-kb EcoRI fragment of ARS1-TRP1 (Tschumper and Carbon 1980) in the pBR322 vector. SPK-3T lacks any RAS genes but is viable because it has the TPK1 gene on a multicopy plasmid (Toda et al. 1987a). (2) T158-5AT (see Table 1) is a tetrad segregant from a diploid T158-T derived from the diploid T158 by transformation with pTPK1-TRP1. T158 is a diploid heterozygous at the CYR1 locus, which encodes adenylyl cyclase (Kataoka et al. 1985a). The CYR1 gene was disrupted by using pcyr1:: URA3, which was constructed as follows. The entire coding sequence of the CYR1 gene (Kataoka et al. 1985a) was removed by digesting pCYR1-2 (Kataoka et al. 1985a) with PvuII and BalI. These enzymes cleave in the $5^{\prime}$ - and $3^{\prime}$-flanking regions of CYR1, respectively. The PvuII to Ball region was replaced with the 1.0-kb HindIII/SmaI fragment of URA3. A 2.3-kb BgIII fragment that contained the $U R A 3$ gene and flanking sequences from the CYR1 locus was used for disruption of the CYR1 gene. T158-5AT does not contain a functional CYR1 gene but is viable because it has the TPK1 gene on a multicopy plasmid. (3) T168-6BT (see Table 1) was a segregant of tetrads from a diploid T168-T that was transformed with the plasmid pTPK1-ADE8. T168 is a diploid heterozygous at all of the three TPK genes, which encode the catalytic subunits of the cAMP-dependent protein kinase (Toda et al. 1987a). pTPK1-ADE8 was constructed by inserting the $3.4-\mathrm{kb} B a m H I / B g l I I$ fragment of $A D E 8$ (White et al. 1985) into the BamHI site of pTPK1-TRP1. T168-6BT lacks any functional chromosomal TPK genes but is viable because it has the TPK1 gene on a multicopy plasmid. (4) TT1A-1 has been described (see Table 1; Broek et al. 1987). TT1A-1 lacks a functional chromosomal CDC25 gene but is viable because it has the $C D C 25$ gene on a multicopy plasmid.

To test whether activation of the cAMP pathway can suppress the growth defects of sch $9^{-}$cells, we constructed a strain, S25-31C, in which the chromosomal SCH9 and BCY1 genes are disrupted. We then introduced the $B C Y 1$ gene on a multicopy plasmid and performed plasmid segregation analysis. This allowed us to assess the growth properties of sch $9^{-}$strains in the presence or absence of $B C Y 1$ and, thus, with either normal or increased activity of the cAMP pathway, respectively. Yeast strains containing three functional TPK genes and lacking the $B C Y 1$ gene are phenotypically abnormal (Cannon and Tatchell 1987; Toda et al. 1987b), and cannot be transformed (S. Cameron, unpubl.). The TPK genes are required for these effects; disruption of two of the TPK genes in a strain lessens the severity of the bcy1- phenotype (Cameron et al. 1988) and renders them transformable (S. Cameron, unpubl.). Because we needed to introduce multicopy plasmids by transformation, S25-31C lacks the TPK2 and TPK3 genes (partial genotype: $s c h 9^{-} b c y 1^{-}$TPK1 tpk2- $t p k 3^{-}$) and was constructed by tetrad analysis of a diploid strain made by crossing T198-8B with S13-3A. Activation of any one of the TPK genes through disruption of the $B C Y 1$ gene will suppress the growth defect of an sch $9^{-}$strain (S. Cameron, unpubl.).

\section{Disruption of the SCH9 gene}

To disrupt the SCH9 gene, we constructed the plasmid psch $9:: A D E 8$, as follows. The $6.5-\mathrm{kb}$ HindIII fragment of SCH9 (see Fig. 1) was subcloned into the corresponding site of pUC8 (Viera and Messing 1982). This plasmid was linearized at the single $B g$ III site located in the middle of the coding region of SCH9 (see Fig. 1), and the 3.4-kb BamHI/BglII fragment of $A D E 8$ (White et al. 1985) was inserted, creating psch9 :: ADE8. The 6.4-kb PvuII fragment of psch9 :: ADE8, which contains $A D E 8$ flanked by sequences of $S C H 9$, was used for gene disruption by transforming a diploid TTSD 1.

\section{Construction of the SCH9 overexpressor plasmid}

In characterizing $\mathrm{SCH} 9$ plasmids made by unidirectional deletion (Henikoff 1984), a plasmid, pUC(SCH9A9), was isolated that contains the EcoRI site of pUC19 (Yanisch-Perron et al. 1985), precisely 14 nucleotides $5^{\prime}$ of the initiating ATG of the SCH9 gene. This modified SCH9 gene was used to construct the plasmid YEp $A D H$-SCH9. A 6.4-kb EcoRI/HindIII fragment containing the complete coding sequence of $S C H 9$ was removed from pUC(SCH9A9) and treated with the large fragment of DNA polymerase. This fragment was then ligated into a HindIII cut, vector, pAD-1, which had been treated with the large fragment of DNA polymerase I. pAD-1 is a $L E U 2-2 \mu$ based vector constructed in this laboratory that contains the alcohol dehydrogenase I promoter adjacent to a polylinker (J. Field et al., in prep.). The resulting plasmid, YEp $A D H-S C H 9$, contains the $S C H 9$ gene under the control of the ADH1-gene promoter.

\section{Acknowledgments}

We are grateful to Dr. S. Fogel for providing a plasmid containing the $A D E 8$ gene. We thank M. Riggs for excellent technical assistance, J. Duffy, D. Greene, and M. Ockler for the artwork and photography, and P. Bird for her help in the preparation of this manuscript. This work was supported by grants from the National Institutes of Health, American Business Foundation for Cancer Research, American Cancer Society, and Pfizer Biomedical Research Award. P.S. is supported by the Damon Runyon-Walter Winchell Cancer Fund. S.C. is a graduate student from the Genetics Program at the State University of New York at Stony Brook. M.W. is an American Cancer Society Research Professor.

\section{References}

Biggin, M.D., T.J. Gibson, and G.F. Hong. 1983. Buffer gradient gels and ${ }^{35} \mathrm{~S}$ label as an aid to rapid DNA sequence determination. Proc. Nat1. Acad. Sci. 80: 3963-3965.

Boutelet, F., A. Petitjean, and F. Hilger. 1985. Yeast CDC35 mutants are defective in adenylate cyclase and are allelic with CYR1 mutants while CAS1, a new gene, is involved in the regulation of adenylate cyclase. EMBO J. 4: 2635-2642.

Broek, D., T. Toda, T. Michaeli, L. Levin, C. Birchmeier, M. Zoller, S. Powers, and M. Wigler. 1987. The S. cerevisiae $C D C 25$ gene product regulates the RAS/adenylate cyclase pathway. Cell 48: 789-799.

Cameron, S., L. Levin, M. Zoller, and M. Wigler. 1988. cAMPindependent control of sporulation, glycogen metabolism and heat shock resistance in $S$. cerevisiae. Cell (in press).

Camonis, J.H., M. Kalekine, G. Bernard, H. Garreau, E. BoyMarcotte, and M. Jacquet. 1986. Characterization, cloning and sequence analysis of the CDC25 gene which controls the cyclic AMP level of Saccharomyces cerevisiae. EMBO I. 5: 375-380.

Cannon, J. and K. Tatchell. 1987. Characterization of Saccharomyces cerevisiae genes encoding subunits of cyclic AMP-dependent protein kinase. Mol. Cell. Biol. 7: 2653-2663. 
Dumas, J.P. and J. Ninio. 1982. Fast algorithms to deal with nucleic acid sequences. Nucleic Acids Res. 10: 197-206.

Hannink, M. and D.J. Donoghue. 1985. Lysine residue 121 in the proposed ATP-binding site of the v-mos protein is required for transformation. Proc. Natl. Acad. Sci. 82: 78947898.

Hattori, M. and Y. Sakaki. 1986. Dideoxy sequencing method using denatured plasmid templates. Anal. Biochem. 152: 232-238.

Henikoff, S. 1984. Unidirectional digestion with exonuclease III creates targeted breakpoints for DNA sequencing. Gene 28: $351-359$.

Hunter, T. and J.A. Cooper. 1986. Viral oncogenes and tyrosine phosphorylation. Annu. Rev. Biochem. 54: 897-930.

Ito, H., Y. Fukuda, K. Murata, and A. Kimura. 1983. Transformation of intact yeast cells treated with alkali cations. $I$. Bacteriol. 153: 163-168.

Johnson. K.E., S. Cameron, T. Toda, M. Wigler, and M. Zoller. 1987. Expression in Escherichia coli of $B C Y 1$, the regulatory subunit of the cAMP-dependent protein kinase from Saccharomyces cerevisiae. J. Biol. Chem. 262: 8636-8642.

Kamps, M.P., S.S. Taylor, and B.M. Sefton. 1984. Direct evidence that oncogenic tyrosine protein kinases and cAMP-dependent protein kinase have homologous ATP-binding sites. Nature 310: 589-592.

Kataoka, T., D. Broek, and M. Wigler. 1985a. DNA sequence and characterization of the $S$. cerevisiae gene encoding adenylate cyclase. Cell 43: 493-505.

Kataoka, T., S. Powers, S. Cameron, O. Fasano, M. Goldfarb, J.R. Broach, and M. Wigler. 1985b. Functional homology of mammalian and yeast RAS genes. Cell 40: 19-26.

Knopf, J.L., M.-H. Lee, L.A. Sultzmann, R.W. Kriz, C.R. Loomis, R.M. Hewick, and R.M. Bell. 1986. Cloning and expression of multiple protein kinase C cDNA's. Cell 46: 491-502.

Lisziewicz, I.A., H. Godany, H. Foerster, and H. Kuentzel. 1987. Isolation and nucleotide sequence of a Saccharomyces cere. visiae protein kinase gene suppressing the cell cycle start mutation cdc25. J. Biol. Chem. 262: 2549-2553.

Lorincz, A.T. and S.I. Reed. 1983. Primary structure homology between the product of yeast cell division control gene CDC28 and vertebrate oncogenes. Nature 307: 183-185.

Maniatis, T., E.F. Fritsch, and J. Sambrook. 1982. Molecular cloning: A laboratory manual. Cold Spring Harbor Laboratory, Cold Spring Harbor, New York.

Marshall, M.S., J.B. Gibbs, E.M. Scolnick, and I.S. Sigal. 1987. Regulatory function of the Saccharomyces cerevisiae RAS C-terminus. Mol. Cell. Biol. 7: 2309-2315.

Martegani, E., M.D. Baroni, and M. Wanoni. 1986a. Interaction of cAMP with the CDC25-mediated step in the cell cycle of Saccharomyces cerevisiae. EMBO I. 5: 375-380.

Martegani, E., M.D. Baroni, G. Frascotti, and L. Alberghina. 1986b. Molecular cloning and transcriptional analysis of the start gene CDC25 of Saccharomyces cerevisiae. EMBO $/$. 5: $2363-2369$.

Matsumoto, K., I. Uno, and T. Ishikawa. 1984. Identification of the structural gene and nonsense alleles for adenylate cyclase in Saccharomyces cerevisiae. J. Bacteriol. 157: 277287.

Matsumoto, K., I. Uno, Y. Oshima, and T. Ishikawa. 1982. Isolation and characterization of yeast mutants deficient in adenylate cyclase and cAMP-dependent protein kinase. Proc. Natl. Acad. Sci. 79: 2355-2359.

Nasmyth, K.A. and S.I. Reed. 1980. Isolation of genes by complementation in yeast: Molecular cloning of a cell cycle gene. Proc. Natl. Acad. Sci. 77: 2119-2123.

Needleman, S.B. and C.D. Wunsch. 1970. A general method ap- plicable to the search for similarities in the amino acid sequences of two proteins. J. Mol. Biol. 48: 443-453.

Nikawa, J., P. Sass, and M. Wigler. 1987a. Cloning and characterization of the low-affinity cyclic AMP phosphodiesterase gene of Saccharomyces cerevisiae. Mol. Cell. Biol. 7: 36293636.

Nikawa, J., S. Cameron, T. Toda, K.M. Ferguson, and M. Wigler. 1987b. Rigorous feedback control of cAMP levels in Saccharomyces cerevisiae. Genes Dev. 1: 931-937.

Powers, S., T. Kataoka, O. Fasano, M. Goldfarb, J. Strathern, J.R. Broach, and M. Wigler. 1984. Genes in S. cerevisiae encoding proteins with domains homologous to the mammalian ras proteins. Cell 36: 607-612.

Rasmussen, H. 1986. The calcium messenger system. N. Engl. J. Med. 314: 1094-1101, 1164-1170.

Reimann, E.M., K. Titani, L.H. Ericsson, R.D. Wade, E.H. Fischer, and K.A. Walsh. 1984. Homology of the gammasubunit of phosphorylase-b kinase with cAMP-dependent protein kinase. Biochemistry 23: 4185-4192.

Rivin, C.J. and W.L. Fangmann. 1980. Cell-cycle phase expansion in nitrogen-limited cultures of Saccharomyces cerevisiae. J. Cell. Biol. 85: 96-107.

Robinson, L.C., J.B. Gibbs, M.S. Marshall, I.S. Sigal, and K. Tatchell. 1987. CDC25: A component of the RAS-adenylate cyclase pathway in Saccharomyces cerevisiae. Science 235: $1218-1221$.

Rothstein, R.J. 1983. One-step gene disruption in yeast. Methods Enzymol. 101: 202-211.

Sanger, F., S. Nicklen, and A.R. Coulson. 1977. DNA sequencing with chain-terminating inhibitors. Proc. Natl. Acad. Sci. 74: 5463-5467.

Sass, P., J. Field, J. Nikawa, T. Toda, and M. Wigler. 1986. Cloning and characterization of the high affinity cAMP phosphodiesterase of S. cerevisiae. Proc. Natl. Acad. Sci. 83: 9303-9307.

Sherman, F., G.R. Fink, and J.B. Hicks. 1986. In Laboratory course manual for methods in yeast genetics. (ed. F. Sherman, G.R. Fink, and J.B. Hicks) Cold Spring Harbor Laboratory, Cold Spring Harbor, New York.

Shoji, S., D. Parmelee, R. Wade, S. Kumar, L. Ericsson, K. Walsh, H. Neurath, G. Long, J. Demaille, E. Fischer, and K. Titani. 1981. Complete amino acid sequence of the catalytic subunit of bovine cardiac muscle cyclic AMP-dependent protein kinase. Proc. Natl. Acad. Sci. 78: 848-851.

Showers, M.O. and R.A. Mauver. 1986. A cloned bovine cDNA encodes an alternate form of the catalytic subunit of cAMPdependent protein kinase. J. Biol. Chem. 261: 16288-16291.

Takio, K., R.D. Wade, S.B. Smith, E.G. Krebs, K.A. Walsh, and K. Titani. 1984. Guanosine cyclic 3', $5^{\prime}$-phosphate dependent protein kinase, a dimeric protein homologous with 2 separate protein families. Biochemistry 23: 4207-4218.

Teague, M.A., D.T. Chaleff, and B. Errede. 1986. Nucleotide sequence of the yeast regulatory gene STE7 predicts a protein homologous to protein kinsaes. Proc. Natl. Acad. Sci. 83: $7371-7375$.

Toda, T., S. Cameron, P. Sass, M. Zoller, and M. Wigler. 1987a. Three different genes in $S$. cerevisiae encode the catalytic subunits of the cAMP-dependent protein kinase. Cell 50: 277-287.

Toda, T., S. Cameron, P. Sass, M. Zoller, J.D. Scott, B. McMullen, M. Hurwitz, E.G. Krebs, and M. Wigler. 1987b. Cloning and characterization of $B C Y 1$, a locus encoding a regulatory subunit of the cAMP dependent protein kinase in Saccharomyces cerevisiae. Mol. Cell. Biol. 7: 1371-1377.

Toda, T., I. Uno, T. Ishikawa, S. Powers, T. Kataoka, D. Broek, S. Cameron, J.R. Broach, K. Matsumoto, and M. Wigler. 
1985. In yeast, RAS proteins are controlling elements of adenylate cyclase. Cell 40: 27-36.

Tschumper, G. and J. Carbon. 1980. Sequence of a yeast DNA fragment containing a chromosomal replicator and the TRP1 gene. Gene 10: 157-166.

Viera, J. and J. Messing. 1982. The pUC plasmids, an M13up7derived system for insertion mutagenesis and sequencing with synthetic universal primers. Gene 19: 259-268.

White, J.H., K. Lusnak, and S. Fogel. 1985. Mismatch-specific post-meiotic segregation frequency in yeast suggests a heteroduplex recombination intermediate. Nature 315: 350352.

Wilbur, W.J. and D.J. Lipman. 1983. Rapid similarity searches of nucleic acid and protein data banks. Proc. Natl. Acad. Sci. 80: $726-730$.

Yanisch-Perron, C., J. Vieira, and J. Messing. 1985. Improved M13 phage cloning vectors and host strains: Nucleotide sequences of the $\mathrm{Ml3mpl} 8$ and pUC19 vectors. Gene 33: $109-119$.

Zoller, M.J., N.C. Nelson, and S.S. Taylor. 1981. Affinity labeling of cAMP-dependent protein kinase with p-fluorosulfonyl benzoyl adenosine. Covalent modification of lysine 71. J. Biol. Chem. 256: 10837-10842.

Zoller, M.J., J. Kuret, S. Cameron, L. Levin, and K. Johnson. 1988. Purification of C1, the catalytic subunit of Saccharomyces cerevisiae cAMP-dependent protein kinase encoded by TPK1. J. Biol. Chem. (in press). 


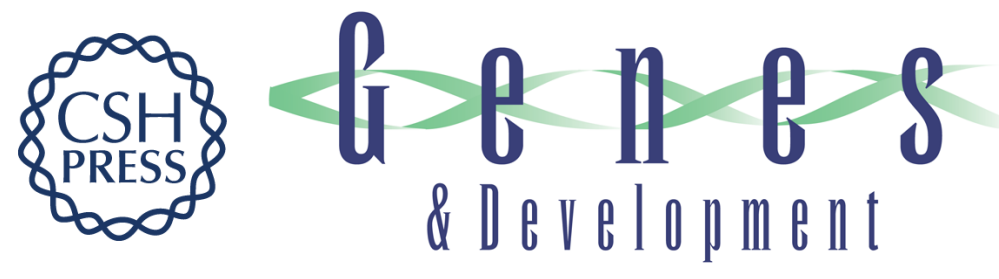

\section{$\mathrm{SCH}$, a gene of Saccharomyces cerevisiae that encodes a protein distinct from, but functionally and structurally related to, cAMP-dependent protein kinase catalytic subunits.}

T Toda, S Cameron, P Sass, et al.

Genes Dev. 1988, 2:

Access the most recent version at doi:10.1101/gad.2.5.517

References This article cites 48 articles, 22 of which can be accessed free at: http://genesdev.cshlp.org/content/2/5/517.full.html\#ref-list-1

License

Email Alerting Service

Receive free email alerts when new articles cite this article - sign up in the box at the top right corner of the article or click here.

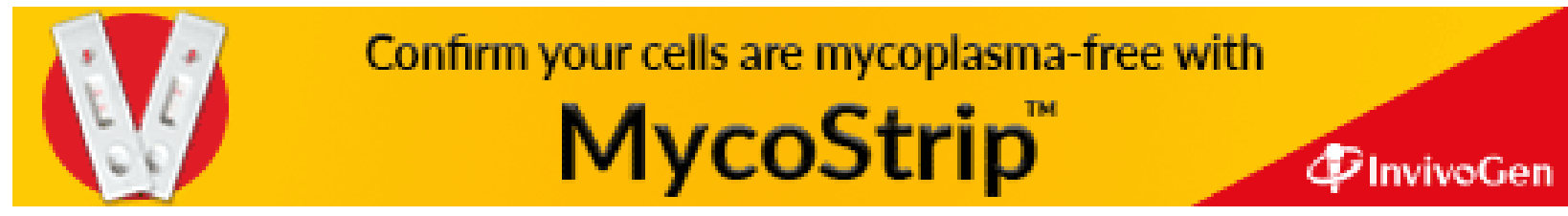

